\title{
Análise de preços hedônicos no mercado imobiliário residencial de Conselheiro Lafaiete, MG
}

\author{
Analysis of hedonic prices in the residential real estate market of \\ Conselheiro Lafaiete, MG
Analyse des prix hedoniques dans le marché immobilier résidentiel de Conselheiro Lafaiete, MG

\section{Análisis de precios hedónicos en el mercado inmobiliario residencial de Conselheiro Lafaiete, MG}

\author{
Victor Henrique Lana Pinto ${ }^{1}$ \\ Rosangela Aparecida Soares Fernandes ${ }^{2}$ \\ Recebido em 15/12/2017; revisado e aprovado em 07/05/2018; aceito em 14/05/2018 \\ DOI: http://dx.doi.org/10.20435/inter.v20i2.1788
}

\begin{abstract}
Resumo: O presente artigo consiste na análise dos atributos relevantes na formação dos preços de imóveis residenciais para venda em Conselheiro Lafaiete, MG, em 2016. Estimou-se um modelo hedônico a partir de uma regressão linear múltipla, que permitiu associar o preço dos imóveis às características dos bens imobiliários e de seu entorno. Os resultados sugerem que as variáveis foram relevantes para explicar a variabilidade nos preços dos imóveis, e refletiram a realidade do mercado imobiliário de Conselheiro Lafaiete. Palavras-chave: modelo de preços hedônicos; economia urbana; índice de preços para bens imóveis.

Abstract: The present article consists of the analysis of the relevant attributes in the formation of the prices of residential properties for sale in Conselheiro Lafaiete, MG, in 2016. A hedonic model was estimated from a multiple linear regression that allowed to associate the real estate price with the properties' characteristics and its surroundings. The results suggest that the variables were relevant to explain the variability in real estate prices, and reflected the reality of the real estate market of Conselheiro Lafaiete.
\end{abstract}

Keywords: hedonic price model; urban economics; real estate price indexes.

Résumé: Le présent article consiste en l'analyse des attributs pertinents dans la formation des prix des propriétés résidentielles à vendre à Conselheiro Lafaiete, MG, en 2016. Un modèle hédonique a été estimé à partir d'une régression linéaire multiple qui a permis d'associer le prix de l'immobilier avec les caractéristiques de l'immobilier et de son environnement. Les résultats suggèrent que les variables étaient pertinentes pour expliquer la variabilité des prix de l'immobilier et reflétaient la réalité du marché immobilier de Conselheiro Lafaiete.

Mots-clés: modèle de prix hédonique; economie urbaine; indice des prix pour l'immobilier.

Resumen: El presente artículo consiste en el análisis de los atributos relevantes en la formación de los precios de las propiedades residenciales para la venta en Conselheiro Lafaiete, MG, en 2016. Se estimó un modelo hedónico a partir de una regresión lineal múltiple que permitió asociar el precio del inmueble con las características inmobiliarias y su entorno. Los resultados sugieren que las variables fueron relevantes para explicar la variabilidad en los precios inmobiliarios y reflejaron la realidad del mercado inmobiliario de Conselheiro Lafaiete.

Palabras clave: modelo de precios hedónicos; economía urbana; índice de precios para bienes inmuebles.

\footnotetext{
${ }^{1}$ Universidade Federal de Viçosa (UFV), Viçosa, Minas Gerais, Brasil.

${ }^{2}$ Universidade Federal de Ouro Preto (UFOP), Ouro Preto, Minas Gerais, Brasil.
} 


\section{INTRODUÇÃO}

Conselheiro Lafaiete está localizada na região central de Minas Gerais, situada a cerca de 96 km de Belo Horizonte, na região do Alto Paraopeba. Segundo dados do Instituto Brasileiro de Geografia e Estatística (IBGE, 2017), Conselheiro Lafaiete é o 22o município mais populoso do estado e o 1 으 da microrregião, com cerca de 127 mil habitantes. A cidade integra o circuito turístico Villas e Fazendas ${ }^{3}$ e possui atrativos como parques e horto florestal. A atividade econômica de Conselheiro Lafaiete está, em grande parte, atrelada à presença de empresas de pequeno, médio e grande porte dos setores industrial, comercial e de prestação de serviços.

O desenvolvimento econômico da cidade ocorre em um cenário de ampliação da oferta de qualificação profissional no ensino técnico e superior, proporcionado por instituições privadas e públicas localizadas no município e em seu entorno. Tudo isso, traz impactos sobre o mercado imobiliário lafaietense, pois não somente a população local, mas também trabalhadores empregados nas indústrias siderúrgica, extrativa, em instituições de ensino e nos variados estabelecimentos comerciais, que trabalham inclusive em municípios vizinhos, suprem suas necessidades habitacionais em Conselheiro Lafaiete. Com isso, observa-se uma maior demanda pelo consumo de habitação na cidade, fato que contribui para o aquecimento do setor imobiliário no município mineiro.

Compreender o comportamento dos preços de venda dos imóveis residenciais é de grande importância para a economia, pois é através destes estudos que são feitas estimações quanto a demanda do setor (MEDEIROS; CARVALHO, 2017). Tais pesquisas devem ser o mais próximo da realidade possível, e diferentes metodologias podem ser empregadas, destacando-se os modelos de regressão linear múltipla e de precificação hedônica (FERNANDES; MOREIRA; SILVA, 2010). Nessa situação, o modelo de preços hedônicos desenvolvido por Court (1939) é particularmente importante, e deve ser amplamente utilizado para mensurar a disposição marginal a pagar de um consumidor por determinada característica do bem. Especificamente no mercado imobiliário, essa metodologia permite estimar quais variáveis impactam o valor das moradias, oferecendo também, ferramentas para que possam ser desenhadas políticas públicas que visem ao aumento do bem-estar dos indivíduos.

Mediante esse cenário, este artigo tem como objetivo principal analisar o mercado de imóveis residenciais para compra no município de Conselheiro Lafaiete, Minas Gerais em 2016. Além desta introdução, este trabalho está dividido em mais cinco seções. A segunda seção apresenta um panorama de Conselheiro Lafaiete. A terceira trata do referencial teórico de suporte às teorias de formação dos preços e dos fatores de valorização de imóveis residenciais. Na quarta seção, a descrição da base de dados empregada no trabalho, com informações sobre as variáveis utilizadas na análise econométrica. Na quinta seção, os resultados. Por fim, a sexta seção apresenta as considerações finais.

\footnotetext{
${ }^{3}$ Circuito turístico composto por antigas vilas e fazendas ligadas a história do Brasil Colônia, do Império (SERVIÇO NACIONAL DE APRENDIZAGEM COMERCIAL [SENAC], 2015)
} 


\section{BREVE PANORAMA DA CIDADE DE CONSELHEIRO LAFAIETE}

A cidade de Conselheiro Lafaiete, localizada na Mesorregião Metropolitana de Belo Horizonte, é a mais populosa da região do Alto Paraopeba (IBGE, 2010). Segundo último censo divulgado, sua população estimada para 2017 foi de 127.369 habitantes, com um Produto Interno Bruto (PIB) per capita de R\$14.952,68. O PIB do município é oriundo dos setores agropecuário, industrial e de serviços (IBGE, 2017). Este último, responsável pela maior contribuição no valor do PIB da cidade conforme apresentado na Tabela 1.

Tabela 1 - Produto Interno Bruto por setores da economia em reais em 2013

\begin{tabular}{lcc}
\hline Setores & Conselheiro Lafaiete & Minas Gerais \\
\hline Agropecuária & 9.121 & 15.568 .048 \\
Indústria & 211.054 & 54.306 .183 \\
Serviços & 991.368 & 97.398 .820 \\
\hline
\end{tabular}

Fonte: IBGE (2017).

A Tabela 1 acima reporta a relevância do setor de serviços como principal fonte de geração de renda do município, pois é o segmento que mais contribui para a economia do município, assim como ocorre no estado de Minas Gerais como um todo.

A presença de grandes empresas mineradoras e siderúrgicas, tais como Vale, MRS Logística, Gerdau, Companhia Siderúrgica Nacional (CNS) e Vallourec Sumitomo Tubos do Brasil (VSB) em cidades vizinhas (Ouro Branco, Congonhas e Jeceaba), pode vir a representar a influência da atividade industrial na economia local. Além disso, a localização da cidade, na região metropolitana de Belo Horizonte, pode ser considerada estratégica uma vez que a condição do município como um polo de serviços atrai investimentos das empresas mineradoras e siderúrgicas citadas acima.

Segundo o Conselho Estratégico de Desenvolvimento Econômico do Alto Paraopeba (CEDECAP, 2015), a atividade comercial em Conselheiro Lafaiete agrega vários empreendimentos (corresponde a $80 \%$ do PIB do município), indústria e extração de manganês. As empresas de médio e pequeno porte promovem as atividades industriais na região, além de diversas empresas no segmento de serviços. A cidade tem posição privilegiada em termos de logística ferroviária e rodoviária, por ser "cortada" de norte a sul pela Ferrovia Centro Atlântica (FCA) e as margens das rodovias BR-040, BR-482 e MG-129, principais rotas de escoamento da produção das grandes indústrias, ficando no eixo Belo Horizonte-Rio de Janeiro, próxima aos grandes consumidores da região e de empresas minero-siderúrgicas.

O Distrito Industrial do município está situado a apenas $3 \mathrm{~km}$ do centro do município. Concomitantemente, é um polo comercial com estabelecimentos variados, dentre eles: concessionárias de automóveis, armarinhos, venda de eletrodomésticos, gêneros alimentícios, calçados, confecções, postos de gasolina. As condições de acesso às atividades econômicas, incentiva a migração de pessoas de outras regiões e favorece a circulação de trabalhadores e estudantes para os municípios da região. A Tabela 2, abaixo, apresenta o crescimento populacional no município de Conselheiro Lafaiete, no período entre 1991 a 2015. 
Tabela 2 - Expansão demográfica na cidade de Conselheiro Lafaiete, 1991-2015

\begin{tabular}{lcc}
\hline Ano & Conselheiro Lafaiete & Minas Gerais \\
\hline $\mathbf{1 9 9 1}$ & 89.059 & 15.743 .152 \\
$\mathbf{1 9 9 6}$ & 94.270 & 16.567 .989 \\
$\mathbf{2 0 0 0}$ & 102.836 & 17.891 .494 \\
$\mathbf{2 0 0 7}$ & 109.280 & 19.273 .506 \\
$\mathbf{2 0 1 0}$ & 116.512 & 19.597 .330 \\
$\mathbf{2 0 1 5}$ & 125.421 & 20.869 .101 \\
\hline
\end{tabular}

Fonte: IBGE (2010).

Um dos fatores que pode explicar esse crescimento populacional nos últimos anos é o aumento dos investimentos no setor minero-siderúrgico no Alto Paraopeba, considerado um dos principais polos dessa atividade. Ressalta-se qu, a expansão desse setor na região gera efeitos multiplicadores sobre a atividade comercial dos municípios limítrofes, aumentando a demanda por infraestrutura, serviços e habitação.

Adicionalmente, os centros de ensino também se inserem como instrumento de polarização populacional em Conselheiro Lafaiete, especialmente no que se refere à educação profissionalizante. Atendendo as necessidades de qualificação e inserção no mercado de trabalho, a região possui várias unidades de ensino, com destaque ao campus Alto Paraopeba da Universidade Federal de São João Del Rey (UFSJ) e três campi do Instituto Federal de Minas Gerais (IFMG) nas cidades de Congonhas, Conselheiro Lafaiete e Ouro Branco.

No município de Conselheiro Lafaiete, tem-se a Universidade Presidente Antônio Carlos (UNIPAC), Faculdade Santa Rita (FASAR), Faculdade de Direito de Conselheiro Lafaiete (FDCL) Centro de Ensino Superior (CES), polo da Universidade Aberta do Brasil (UAB), além de diversos cursos de ensino à distância, escolas técnicas, a presença de duas unidades do SENAC e uma unidade do Serviço Brasileiro de Apoio às Micro e Pequenas Empresas (SEBRAE). Essa realidade também contribui para expansão populacional e o consequente aumento na demanda por habitação e demais serviços na cidade de Conselheiro Lafaiete.

Mediante esse cenário, é possível inferir que a cidade tem passado por um crescimento expressivo do mercado imobiliário. Verifica-se, em Conselheiro Lafaiete, que existem investimentos imobiliários em vários pontos do município, entretanto, grande parte das casas pesquisadas está fora do centro, Figura 1, abaixo:

Figura 1 - Percentual de imóveis disponíveis para vendas no centro comercial e demais localidades

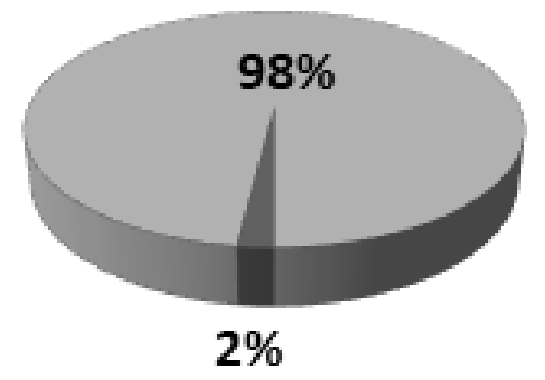

\author{
Centro \\ $\square$ Fora do Centro
}

Fonte: Dados da pesquisa. 
A região central da cidade é predominantemente comercial, com inúmeras lojas, restaurantes, estacionamentos, empresas e hotéis, o que reduz as possibilidades de encontrar residências a venda nesse local. Ressalta-se que atualmente, a cidade possui mais de 4.000 estabelecimentos comerciais que oferecem os mais variados tipos de serviços como bares, padarias, açougues, sapatarias, vestuário, distribuidoras, comércio e indústria de materiais de construção, móveis, concessionárias, produtos agrícolas, lubrificantes, papelaria, tecidos em geral, serviços em geral, confecções de roupa, eletrodomésticos, informática, bancas de revistas, artigos religiosos etc.

Por ser um município com desenvolvimento econômico e um crescimento relativamente maior que as cidades vizinhas, Conselheiro Lafaiete possui um mercado imobiliário abrangente. Nos últimos anos é crescente a expansão no setor da construção civil. O processo de crescimento urbano, por meio de elevados números de construções (residenciais e comerciais), criação de novos bairros e verticalização da cidade, tornou o mercado imobiliário altamente rentável para empresas do ramo e proprietários de imóveis. De acordo com o Conselho Regional de Corretores de Imóveis (CRECI-MG, s.d.) a cidade de Conselheiro Lafaiete possui 126 corretores ativos no mercado e 14 imobiliárias em atividade registradas, além de grandes construtoras.

Em suma, constata-se que o mercado imobiliário no município de Conselheiro Lafaiete apresenta características diversas, tanto no que se refere à oferta quanto à demanda. Afirmações, prévias sobre os principais determinantes dos preços dos imóveis residenciais nessa cidade, devem ser realizadas de forma cautelosa, uma vez que se faz necessário realizar uma investigação empírica envolvendo diferentes variáveis, a fim de se obter resultados mais robustos que subsidiem discussões futuras.

\section{REVISÃO DE LITERATURA}

O mercado habitacional, do ponto de vista de geração de empregos e renda para o sistema econômico e também no que tange à importância social do produto habitação, é um setor chave da economia. A compreensão do seu funcionamento é fundamental para a elaboração e a implementação de políticas habitacionais e urbanas (DANTAS; MAGALHÃES; VERGOLINO, 2010).

A estrutura de preços do mercado imobiliário tem sido estudada não exclusivamente pelo custo da construção, mas também a partir de modelos que estimam o preço de uma determinada unidade residencial pelos atributos por ela apresentadas (LEEUW, 1993). A tradicional abordagem da função da utilidade deve incorporar, segundo Lancaster (1966), um enfoque mais amplo para a Teoria do Consumidor, na qual a utilidade não é obtida unicamente pelo bem próprio, mas sim, por suas características. Assume-se assim que o bem não propicia utilidade ao consumidor, mas possui atributos que o fazem.

Os bens imóveis que constituem o mercado imobiliário possuem características peculiares, uma vez que são tanto bens de uso quanto bens de investimento. Esse mercado é distinto dos demais, como o de automóveis, de eletrodomésticos e de outros bens dessa natureza (MATTA, 2007). Os principais fatores que o distinguem são: a vida útil elevada, a singularidade, a sua localização, e as interferências das leis municipais, estaduais ou federais (PELLI NETO, 2003). Diferentemente de outros bens nos quais as características não são muito distintas, os imóveis do mercado imobiliário são singulares. Assim, por mais semelhantes que sejam dois imóveis, pelo menos uma de suas características será diferente, como localização ou posição. Portanto, não há no mercado imobiliário um imóvel igual a outro. 
O mercado imobiliário, constituído tanto por bens disponíveis para locação ou para aquisição, sofre, assim como os demais mercados, com as oscilações de oferta e demanda de mercado. Com o intuito de descobrir em qual ponto encontra-se o equilíbrio, é necessário analisar o comportamento dos determinantes dos preços nesses mercados, que são repletos de assimetria de informação e falhas (ARRAES; SOUSA FILHO, 2008).

Os trabalhos existentes na literatura que têm como objetivo analisar o mercado imobiliário (para venda e locação), usualmente baseiam-se no modelo de precificação hedônica. Tal modelo tem sido amplamente usado para avaliar as características de mercados residenciais urbanos, uma vez que se refere a valores implícitos dessas características, nas unidades residenciais (FÁVERO; LUPPE, 2006). Especificamente, os modelos hedônicos também são empregados nas análises de economia urbana e na mensuração dos impactos de políticas urbanas e sociais no mercado imobiliário.

Segundo Rosen (1974), preços hedônicos são definidos como preços implícitos dos atributos e são revelados a partir daqueles observados de produtos diferenciados, e das respectivas características agregadas a eles. Econometricamente, preços implícitos são estimados a partir da análise de regressão linear múltipla por meio da qual os preços dos produtos são regredidos em função de suas características (ÂNGELO; FÁVERO, 2003).

De acordo com Dantas, Magalhães e Vergolino (2007), a metodologia hedônica permite fazer uma avaliação confiável do valor do bem habitação. Portanto esse método é importante tanto na esfera privada quanto na pública, uma vez que serve de parâmetro para a tomada de decisões. Destaca-se que um bem imóvel residencial oferece diversos serviços, chamados de habitação, cujas características estruturais são: a área construída, o padrão construtivo, o número de vagas na garagem, entre outras, e características locacionais, que consideram o bairro onde o imóvel está situado, a distância em relação aos polos de influência e etc. Tais atributos não são precificados pelo mercado, mas podem ser medidos a partir de modelos econométricos, permitindo que se tenha o conhecimento do preço marginal que o consumidor está disposto a pagar por esses serviços agregados ao imóvel. O conhecimento do valor implícito no preço da habitação, de acordo com esses autores, é de grande contribuição para a elaboração e implantação de políticas habitacionais e urbanas por parte dos empreendedores urbanos e do poder público, pois, no longo prazo, são as preferências do consumidor que determinam a configuração das cidades.

\section{METODOLOGIA}

A precificação dos imóveis exige estratégias que permitam revelar a influência do ambiente nesse contexto de ausência de informação via mercado. Nessa situação, o modelo de preços hedônicos desenvolvido por Court (1939) é particularmente importante, e deve ser amplamente utilizado para mensurar a disposição marginal a pagar de um consumidor por determinada característica do bem. Especificamente no mercado imobiliário, essa metodologia permite estimar quais variáveis impactam o valor das moradias, oferecendo, também, ferramentas para que possam ser desenhadas políticas públicas que visem ao aumento do bem-estar dos indivíduos.

O modelo de regressão linear múltipla é assim denominado, pois, possui mais de um regressor. A expressão com k regressores, pode ser escrita na forma normal e reduzida, como expressas nas equações 1 e 2 : 
$Y=\beta_{0}+\beta_{1} X_{1}+\beta_{2} X_{2}+\ldots \ldots \ldots \ldots \ldots+\beta_{k} X_{k}+\varepsilon$

$Y=\beta_{0}+\sum_{j=1}^{n} \beta_{j} X_{j}+\varepsilon$

Em que $Y$ é a variável dependente, $X_{j}, j=0,1, \ldots . . n$ são as variáveis independentes, $\boldsymbol{E}$ são os coeficientes de regressão, ou seja, são os parâmetros que representam a variação esperada em $Y$ por unidade de variação em $X_{j}$, quando todos os demais regressores são mantidos constantes e $\varepsilon$ é um termo de erro aleatório que contém a variabilidade em Y, e não é explicada pelos regressores da equação. Para encontrar os estimadores dos $\beta$ s deve-se minimizar a soma dos quadrados dos erros pelo método dos Mínimos Quadrados Ordinários (MQO), (GUJARATI; PORTER, 2011). Verifica-se que a soma dos quadrados dos erros é definida pela forma:

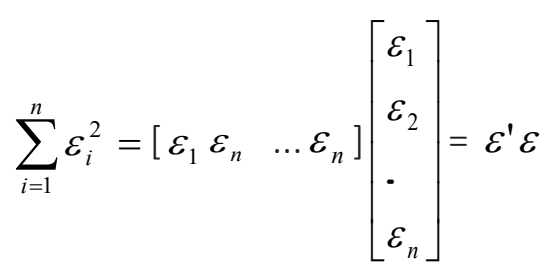

É importante observar que:

$Y=X \beta+\varepsilon=>Y-X \beta=\varepsilon^{\prime}=(Y-X \beta)$

Assim, a soma dos quadrados dos erros é determinada por:

$L=\varepsilon^{\prime} \varepsilon=(Y-X \beta)(Y-X \beta)$

A solução do problema de minimização da soma dos quadrados dos erros é dada por:

$$
\frac{\partial L}{\partial \beta}=0
$$

De outro modo, $X^{\prime} X \beta=X^{\prime} Y$.

\subsection{Seleção das variáveis}

A escolha das variáveis incluídas neste artigo estão aportadas nos estudos pesquisados. A literatura faz uso de diversas características dos imóveis que são influenciadoras, em alguma medida, na precificação dos bens imobiliários residenciais. Esses atributos, chamados aqui de Características Intrínsecas $(\mathrm{Cl})$, se referem à aspectos físicos dos imóveis, tais como número de quartos, banheiros, garagem, área total etc. Buscou-se também incluir variáveis de controle relativas ao perfil social do município de Conselheiro Lafaiete para capturar efeitos exógenos às características construtivas dos bens que também podem afetar o preço de venda das unidades imobiliárias residenciais na cidade. Os controles utilizados, divididos neste trabalho em Localização e Acessibilidade (LA) e Amenidades (A), abrangem as distâncias dos imóveis em relação ao centro comercial e a áreas de lazer bem como a presença de instituições de ensino e saúde nos bairros onde os imóveis estão localizados. Nesse sentido, o conjunto de variáveis $\mathrm{Cl}$, LA e A visa capturar as peculiaridades do mercado imobiliário para venda no município de Conselheiro Lafaiete, MG relacionadas aos aspectos físicos e locacionais dos bens, conforme equação (3), especificada abaixo: 


$$
\operatorname{lnPR}_{i}=\alpha+\sum_{j=1}^{n} \beta_{j} Z_{i}+\text { rescola }_{i}+\text { Ohospital }_{i}+\delta \text { casa }_{i}+\varepsilon_{i}
$$

Em que $P R_{i}$ se refere ao preço de cada imóvel e o subscrito $i$ indica cada unidade imobiliária. $Z_{i}$ representa um vetor contendo as Características Intrínsecas $(\mathrm{Cl})$ e os fatores de Localização e Acessibilidade (LA). Considera-se nesse modelo como $\mathrm{Cl}$ o número de banheiros sociais, número de suítes (quarto com banheiro), número de quartos, de vagas de garagens e tamanho do imóvel.

Localização e Acessibilidade abarcam a distância entre a unidade imobiliária e o centro comercial, um clube desportivo privado, e uma praça pública de recreação. Para indicar o centro comercial da cidade de Conselheiro Lafaiete, considera-se a região do município que emprega mais mão de obra no setor de serviços e na qual existe maior número de pontos comerciais que podem atrair os demandantes por imóveis residenciais. Para compor as variáveis relativas à lazer, considera-se o maior clube desportivo privado da região, que integra facilidades ligadas ao entretenimento e uma praça pública que oferece diversas possibilidades relacionadas a esportes e recreação.

As variáveis escola e hospital integram o conjunto Amenidades e são indicadas por variáveis binárias que representam, respectivamente, a presença de instituições de ensino público/privado e de hospitais no bairro em que o imóvel está localizado. Por fim, mas não menos importante, casa é uma variável dummy que assume valor 1 se o imóvel $i$ representa uma casa e zero caso contrário (apartamento). $\varepsilon_{i}$ indica o termo de erro aleatório.

\subsection{Fonte de dados}

Para a realização desta pesquisa, utilizou-se uma amostra de imóveis disponíveis para venda (casas e apartamentos) no mercado formal, em Conselheiro Lafaiete, Minas Gerais. Os dados obtidos para este trabalho foram coletados entre os meses de janeiro e abril de 2016. O método de coleta empregado foi através de consulta na internet nos sítios das imobiliárias, cujo objeto social é a prestação de serviços imobiliários em toda a cidade. O conteúdo online disponibilizado pelas agências imobiliárias reúne anúncios de imóveis residenciais de casas e apartamentos com diversas informações referentes às unidades imobiliárias, como por exemplo, seus atributos físicos e locacionais.

A partir dos dados disponibilizados, iniciou-se a coleta dos dados de: valor de venda do imóvel, número de banheiros sociais, número de suítes, número de quartos, número de vagas de garagem, tamanho (área em metros quadrados) e bairro onde o imóvel está situado. A partir da localização em que o imóvel se encontra, calcularam-se as distâncias entre os imóveis e o centro urbano através do Google Maps. Concluída a coleta de dados, obteve-se informações de 81 casas e 69 apartamentos (em um total de 150) bens imóveis disponíveis para venda no mercado formal, em Conselheiro Lafaiete, MG.

\section{RESULTADOS E DISCUSSÃO}

Esta seção se destina, primeiramente, a apresentação dos resultados relativos à estatística descritiva para todas as variáveis incluídas na equação (3). Em um segundo momento, a subseção 4.2 reporta a análise econométrica das variáveis que potencialmente determinam a variabilidade nos preços das unidades imobiliárias residenciais disponíveis para venda no município de Conselheiro Lafaiete, MG. 


\subsection{Estatística descritiva}

A Tabela 3 apresenta os valores médios, desvio padrão e valores extremos para todas as variáveis incluídas no modelo estimado neste estudo.

Tabela 3 - Análise descritiva do mercado imobiliário residencial para venda de Conselheiro Lafaiete

\begin{tabular}{lcccccc}
\hline Variável & Natureza & Obs. & Média & Desvio padrão & Mínimo & Máximo \\
\hline Preço & - & 150 & 377000 & 384045.900 & 90000 & 3300000 \\
Banheiros & $\mathrm{Cl}$ & 150 & 1,33 & 0,598 & 1 & 4 \\
Quartos & $\mathrm{Cl}$ & 150 & 2,12 & 0,926 & 0 & 6 \\
Suíte & $\mathrm{Cl}$ & 150 & 0,68 & 0,606 & 0 & 4 \\
Vagas de garagem & $\mathrm{Cl}$ & 150 & 1,93 & 1,509 & 0 & 9 \\
Tamanho & $\mathrm{Cl}$ & 150 & 131,24 & 89,893 & 46,38 & 790 \\
Distância em relação ao centro & $\mathrm{LA}$ & 150 & 2,99 & 1,922 & 0,10 & 8,8 \\
comercial & & & & & & \\
Distância em relação ao clube & LA & 150 & 3,37 & 1,613 & 0,30 & 10,2 \\
desportivo & $\mathrm{LA}$ & 150 & 3,18 & 1,830 & 0,13 & 8,2 \\
Distância em relação a praça & $\mathrm{A}$ & 150 & 0,49 & 0,502 & 0 & 1 \\
Escola & $\mathrm{A}$ & 150 & 0,06 & 0,238 & 0 & 1 \\
Hospital & - & 150 & 0,46 & 0,500 & 0 & 1 \\
Casa & & &
\end{tabular}

Notas: Preço em reais. Banheiros, quartos, suíte, vagas de garagem em unidades. Tamanho em metros quadrados. Distâncias em quilômetros.

Fonte: Elaboração própria.

A variável dependente 'preço' apresenta valor médio de $\mathrm{R} \$ 377.000$, o que indica o preço médio de venda dos imóveis na cidade de Conselheiro Lafaiete. No entanto o elevado valor do desvio padrão para essa variável sugere que os dados amostrados se posicionam relativamente distantes da média. Isso mostra que a distribuição dos preços de venda dos imóveis em análise varia significativamente e pode vir a configurar um mercado plural e heterogêneo no que diz respeito à oferta de bens imobiliários.

Ao analisar as variáveis que constituem os atributos físicos dos imóveis, ou seja, aquelas que constituem as características intrínsecas dos bens imobiliários, observa-se que os imóveis têm, em média, cerca de um banheiro, dois quartos, uma suíte e duas vagas de garagem por propriedade. Apesar de essas representarem características médias dos imóveis, ao verificar os valores extremos para cada uma das variáveis do conjunto $\mathrm{Cl}$, pode-se perceber que existem atributos que variam bastante em relação à média. Os dados mostram, por exemplo, que existe na amostra pelo menos uma unidade imobiliária que não tem vaga para veículos. Em contrapartida e de maneira análoga, verifica-se também a existência de ao menos uma propriedade que apresenta nove vagas. Os valores extremos para a variável 'número de quartos' mostram uma característica interessante da amostra. Existem unidades que apresentam número nulo de quartos. Assim, buscou-se analisar essas unidades através da base de dados, e percebeu-se que elas possuem número positivo de suítes, ou seja, quartos com banheiros. Valores de máximo e mínimo para a variável 'tamanho do imóvel' também confirmam a diversificação dos imóveis 
que constituem o mercado imobiliário lafaietense. A Tabela 3 indica que existem desde imóveis pequenos, com cerca de $46 \mathrm{~m}^{2}$ até propriedades de elevada metragem quadrada.

No que tange às variáveis de localização e acessibilidade, verifica-se que em média os imóveis estão situados a cerca de três quilômetros do centro comercial, e das principais áreas de lazer. Os valores de máximo, mínimo e desvio em torno da média não permitem muitas afirmações acerca dos imóveis. Nessa etapa da análise dos determinantes de precificação imobiliária da cidade de Conselheiro Lafaiete, pode-se perceber apenas a existência de unidades localizadas mais próximas das áreas de interesse e outras unidades mais distantes. No entanto a análise da relação entre preço e as distâncias poderá ser mais bem compreendida e interpretada na próxima seção, através da análise econométrica.

Escola e hospital compreendem o grupo de variáveis denominado Amenidades. A Tabela 3 indica que apenas 6\% dos bens imobiliários da amostra estão situados em bairros onde há um hospital público ou privado. Em outras palavras, apenas nove das 150 casas e apartamentos investigados estão localizados próximos de um centro de saúde. O número de escolas, como é de se esperar, supera largamente o número de hospitais na cidade. Aproximadamente $49 \%$ ou cerca de 74 dos imóveis analisados se situam em um bairro onde há, no mínimo, uma escola pública ou privada.

\subsection{Determinantes dos preços de imóveis residenciais para venda em Conselheiro Lafaiete}

Esta subseção apresenta as estimações da equação (3) com o intuito de verificar o efeito das variáveis de características intrínsecas, localização e amenidades na precificação dos bens imóveis residenciais em Conselheiro Lafaiete, MG. Tradicionalmente a metodologia para modelagem das estimações de preços hedônicos é o método dos Mínimos Quadrados Ordinários (MQO). Nesse sentido, a Tabela 4 reporta os resultados clusterizados para os 53 bairros (ver Apêndice) sob análise em quatro especificações. A primeira delas (coluna 1) apresenta a estimação incluindo apenas variáveis relativas aos atributos físicos dos imóveis, pertencentes ao grupo $\mathrm{Cl}$. As colunas 2 e 3 mostram os coeficientes estimados para as especificações acrescendo as variáveis dos grupos LA e A, respectivamente. Por fim, a especificação 4, mostra os resultados incluindo a variável binária casa para capturar características específicas das casas e apartamentos que podem ter efeitos distintos sobre os preços dos imóveis amostrados. 
Tabela 4 - Determinantes dos preços de imóveis residenciais para venda em Conselheiro Lafaiete

\begin{tabular}{|c|c|c|c|c|}
\hline Variável dependente: Preço do imóvel & $\mathrm{MQO}(1)$ & MQO (2) & $\mathrm{MQO}(3)$ & $\mathrm{MQO}(4)$ \\
\hline \multirow{2}{*}{ Banheiros } & $0,225^{*}$ & $0,209 *$ & $0,203 *$ & $0,192 *$ \\
\hline & $(0,043)$ & $(0,041)$ & $(0,038)$ & $(0,041)$ \\
\hline \multirow{2}{*}{ Quartos } & $0,123 * *$ & $0,114 * *$ & $0,089 * * *$ & $0,083 * * *$ \\
\hline & $(0,05)$ & $(0,049)$ & $(0,046)$ & $(0,046)$ \\
\hline \multirow{2}{*}{ Suíte } & $0,289 *$ & $0,245^{*}$ & $0,263^{*}$ & $0,271^{*}$ \\
\hline & $(0,09)$ & $(0,077)$ & $(0,073)$ & $(0,07)$ \\
\hline \multirow{2}{*}{ Vagas de garagem } & $0,079 *$ & $0,079 *$ & $0,088^{*}$ & $0,078 *$ \\
\hline & $(0,014)$ & $(0,015)$ & $(0,015)$ & $(0,016)$ \\
\hline \multirow{2}{*}{ Tamanho } & $0,003 *$ & $0,002^{*}$ & $0,002^{*}$ & $0,002 *$ \\
\hline & $(0,001)$ & $(0,001)$ & $(0,001)$ & $(0,001)$ \\
\hline \multirow{2}{*}{ Distância em relação ao centro comercial } & - & $-0,247 *$ & $-0,237 *$ & $-0,271 *$ \\
\hline & - & $(0,078)$ & $(0,062)$ & $(0,075)$ \\
\hline \multirow{2}{*}{ Distância em relação ao clube desportivo } & - & 0,027 & 0,048 & 0,048 \\
\hline & - & $(0,028)$ & $(0,039)$ & $(0,038)$ \\
\hline \multirow{2}{*}{ Distância em relação à praça } & - & $-0,075 * * *$ & $-0,065 * * *$ & $-0,066 * * *$ \\
\hline & - & $(0,043)$ & $(0,037)$ & $(0,039)$ \\
\hline \multirow{2}{*}{ Escola } & - & - & $0,202^{*}$ & $0,203 *$ \\
\hline & - & - & $(0,059)$ & $(0,061)$ \\
\hline \multirow{2}{*}{ Hospital } & - & - & $-0,105$ & $-0,113$ \\
\hline & - & - & $(0,081)$ & $(0,081)$ \\
\hline \multirow{2}{*}{ Casa } & - & - & - & 0,086 \\
\hline & - & - & - & $(0,058)$ \\
\hline \multirow{2}{*}{ Intercepto } & $11,361 *$ & $11,817^{*}$ & $11,728 *$ & $11,783^{*}$ \\
\hline & $(0,102)$ & $(0,125)$ & $(0,11)$ & $(0,129)$ \\
\hline Observações & 150 & 150 & 150 & 150 \\
\hline Estatística F & 118,23 & 93,67 & 99,36 & 78,55 \\
\hline Prob, F & 0,000 & 0,000 & 0,000 & 0,000 \\
\hline R2 & 0,73 & 0,78 & 0,81 & 0,81 \\
\hline
\end{tabular}

Notas: Desvio-padrão em parênteses. ${ }^{*} p<0.01 ;{ }^{* *} p<0.05 ;{ }^{* * *} p<0.1$. Preço do imóvel (em In), distância em relação ao centro comercial (em In), distância em relação ao clube desportivo (em In), distância em relação à praça (em In).

Fonte: Elaboração própria.

Verifica-se, a partir do coeficiente de determinação R2, que as variáveis utilizadas explicam cerca de $81 \%$ (especificação 4) da variabilidade nos preços dos imóveis para venda na cidade de Conselheiro Lafaiete, MG. Mais precisamente, observa-se que o valor de R2 aumentou de aproximadamente $73 \%$ na especificação 1, para cerca de $81 \%$ na especificação 4 , insinuando que as variáveis de localização e amenidades permitem compreender mais amplamente a variabilidade na precificação dos bens imobiliários no município. Ademais, ressalta-se que em todas as especificações os sinais dos coeficientes se mantiveram inalterados e a magnitude das estimações variaram minimamente evidenciando a robustez do modelo.

Os coeficientes das variáveis que compõem o grupo características intrínsecas, ou seja, os atributos físicos das unidades imobiliárias, apresentam sinais coerentes com a literatura de preços hedônicos em todas as especificações. Mais precisamente, a Tabela 4 mostra que as variáveis 
banheiros, quartos, vagas de garagem e tamanho apresentam coeficientes estatisticamente diferentes de zero e positivamente correlacionados com a variável dependente, em consonância com os resultados encontrados por Campos e Almeida (2015). Isso indica que o aumento unitário das quantidades dessas variáveis implica o aumento do preço do bem imobiliário. Esse resultado já era esperado ao se considerar o mercado relevante que demanda os imóveis na cidade. Conforme Brandstetter e Heineck (2005), essas estimativas podem ser explicadas pela busca dos indivíduos por uma moradia maior devido ao nascimento e crescimento dos filhos ou a mudanças induzidas pela formação familiar. A escolha da nova moradia encontra-se, portanto, possivelmente relacionada à composição das famílias no momento da compra e aos eventos que possam alterá-la, permitindo assim melhor explicar a correspondência positiva entre o preço do imóvel e seus atributos intrínsecos.

Como mencionado anteriormente, os resultados relativos aos atributos intrínsecos dos bens são de certo modo passíveis de previsibilidade. Assim, buscou-se incorporar ao modelo econométrico variáveis de localização para capturar eventuais externalidades locacionais, denominadas 'efeitos de vizinhança'. Tais variáveis visam captar as implicações da região e da estrutura dos imóveis próximos, dos padrões de acessibilidade, do contexto socioeconômico local, e das características demográficas, que somados, influenciam o mercado imobiliário (CAN, 1998). Imagina-se que as variáveis do grupo LA sejam negativamente correlacionadas com a variável preço, sugerindo que quanto maior a distância entre os bens e o centro comercial, clube desportivo e praça, menor o preço de venda do imóvel. Similarmente a Ramos (2014), todas as especificações que incluem as variáveis do grupo demonstram resultados estatisticamente significativos e negativamente correlacionados para as distâncias em relação ao centro comercial e à praça de recreação.

A significância da variável distância em relação ao centro comercial pode ser associada à instalação dos imóveis na região central da cidade, o que proporciona aos demandantes benefícios que podem ser somados às decisões de compra. O centro urbano é uma região circundada de facilidades devido à presença de estabelecimentos comerciais como lojas, bancos, farmácias, academias e supermercados que trazem comodidade e praticidade aos proprietários de bens residenciais em seu entorno. Observa-se também que os resultados observados nas especificações 2, 3 e 4 sugerem que os imóveis localizados mais próximos da praça de recreação, possuem valor de venda mais elevado. A significância dessa variável pode ser interpretada pelo fato de a praça proporcionar à comunidade opções gratuitas de lazer, entretenimento e área verde, como quadras desportivas, pistas de corrida e caminhada além de quiosques e restaurantes, sugerindo que os consumidores maximizam a sua utilidade residindo próximo à região da praça, e estão dispostos a pagar pelo 'bem-estar' que esta proporciona

As especificações 2, 3 e 4 indicam que os coeficientes para a variável distância em relação ao clube desportivo são estatisticamente iguais a zero. A não significância dessa variável de controle pode ser interpretada pelo fato de o clube ser privado e, nesse sentido, restringir o acesso de grande parcela da população. Em outras palavras, residir próximo ao clube só maximiza a utilidade do demandante residencial se este for sócio do clube em questão. Caso contrário, muito provavelmente, os demandantes por imóveis em Conselheiro Lafaiete serão indiferentes à localização do clube.

No que tange aos resultados relativos às variáveis do grupo Amenidades, observa-se que os resultados mostrados nas especificações 3 e 4 apontam que existe uma relação positiva e 
estatisticamente significativa entre a presença de escolas no bairro no qual o imóvel está localizado e o preço de venda do bem. Em outras palavras, imóveis que estão inseridos em bairros com ao menos uma escola pública ou privada têm preço de venda mais elevado. Esse efeito "se refere ao impacto que as amenidades, na área em que o imóvel está espacialmente localizado, exercem sobre o preço dos imóveis" (CAMPOS, 2014, p. 07). Além disso, os demandantes por imóveis residenciais próximos de escolas podem se beneficiar da menor dependência de transporte público e particular para realizar suas atividades, uma vez que detêm vantagens locacionais quando comparados a moradores de bairros mais distantes.

Ainda se tratando do grupo Amenidades, similarmente a Campos e Almeida (2015), os coeficientes estimados para a dummy hospital assinalam a não significância estatística de tal variável. Imagina-se que esse resultado se refira ao fato de a presença de um hospital próximo a um imóvel resultar em externalidades negativas aos residentes, como por exemplo, a movimentação de pessoas e veículos durante o dia e também no período noturno. Além disso, compreende-se que os indivíduos acessam os hospitais de maneira pontual, diferentemente do acesso às escolas, por exemplo, reduzindo a dependência dessa amenidade em seu entorno.

Casa representa uma variável binária com o intuito de capturar eventuais diferenças nos efeitos que casas e apartamentos exercem sobre o preço final do bem imóvel. A não significância dessa variável pode ser interpretada pelo fato de as peculiaridades entre casas e apartamentos já estarem sendo incorporadas por outras variáveis do conjunto Cl. É de se esperar, por exemplo, que apartamentos sejam menores e detenham um número inferior de banheiros, quartos, suítes e vagas de garagem em relação às casas.

Em síntese, o mercado imobiliário para venda na cidade de Conselheiro Lafaiete apresenta características bastante peculiares. Verificou-se que o modelo estimado foi eficiente no sentido de explicar a variabilidade nos preços finais de vendas dos imóveis nesse município, uma vez que os coeficientes estimados não apresentaram resultados inconclusivos. Em outras palavras, para todas as variáveis em análise, os efeitos sobre o preço final de venda dos imóveis foram coerentes com a realidade.

\section{CONSIDERAÇÕES FINAIS}

Em função da diversidade do perfil da demanda por imóveis residenciais disponíveis para compra na cidade e por ser um bem que apresenta alto grau de diferenciação, o objetivo geral deste artigo foi analisar o mercado imobiliário para venda na cidade de Conselheiro Lafaiete, Minas Gerais, no primeiro quadrimestre de 2016.

Os resultados revelam que o conjunto de variáveis intrínsecas e a variável dummy escola foram positivamente correlacionadas com a variável dependente, sugerindo que os atributos físicos dos imóveis e a proximidade a instituições de ensino provocam um aumento no valor de venda dos bens imóveis. Como esperado, as variáveis locacionais distância em relação ao centro comercial e em relação à praça foram negativamente correlacionadas com a variável preço. Assim, percebe-se que o mercado residencial valora mais os imóveis disponíveis para compra situados nas proximidades do centro da cidade e da área de recreação considerada. Contrariamente, notou-se a não significância estatística para as variáveis distância relativa ao clube desportivo e hospital. Esses resultados mostram que essas variáveis não detêm efeito sobre a precificação imobiliária residencial na cidade. 
Em síntese, os resultados encontrados neste artigo permitiram uma maior compreensão da dinâmica do mercado imobiliário para venda no município de Conselheiro Lafaiete no período analisado. Apesar de a maioria das variáveis inseridas no modelo ter sido relevante para explicar a variabilidade nos preços de venda dos bens na cidade, notam-se também algumas limitações inerentes a este estudo. Os anúncios através dos websites de oferta imobiliária não garantem que o preço de venda anunciado seja realmente o preço de mercado, uma vez que a negociação entre demandantes e ofertantes pode levar o preço de venda a sofrer alterações. Assim, o preço adequado ao estudo seria o preço do contrato de compra e venda e não o preço anunciado.

Para pesquisas futuras, sugere-se a realização de análises que possam agregar novas informações que reflitam as mudanças ainda mais recentes que vêm afetando, de forma significativa, o mercado imobiliário local, como por exemplo, a criação dos novos loteamentos, acessibilidade facilitada a determinados bairros a partir das recentes obras da prefeitura, construções de novos condomínios, entre outros. O presente trabalho poderá servir como instrumento de consulta não apenas para aqueles que demandam imóveis residenciais para compra, mas também para que as autoridades competentes possam delinear medidas que venham a impactar a dinâmica de funcionamento desse mercado viabilizando a geração de um maior bem-estar social na cidade de Conselheiro Lafaiete, MG.

\section{REFERÊNCIAS}

ÂNGELO, C. F.; FÁVERO, L. P. L. The model of hedonic prices to the evaluation of residential launchings in the city of Sao Paulo. Série de Working Papers da Faculdade de Economia, Administração e Contabilidade da USP, São Paulo, n. 03/002, 2003.

ARRAES, R. A.; SOUSA FILHO, E. Externalidades e formação de preços no mercado imobiliário urbano brasileiro: um estudo de caso. Revista de Economia Aplicada, Ribeirão Preto, SP, v. 12, n. 2, p. 289-319, abr./jun. 2008.

BRANDSTETTER, M. C. G. O.; HEINECK, L. F. M. Aspetos conceituais e metodológicos do comportamento do consumidor do mercado imobiliário: uma caracterização da carreira habitacional. Ambiente Construído, Porto Alegre, v. 5, n. 3, p. 7-21, jul./set. 2005.

CAMPOS, R. B. A.; ALMEIDA, E. S. Decomposição espacial dos preços de imóveis residenciais no município de São Paulo. Working Paper da Faculdade de Economia, Administração e Contabilidade da USP, São Paulo, n. 2015-22, p. 1-21, 2015.

CAMPOS, R. B. A. Dois ensaios sobre economia urbana: mercado imobiliário residencial e corporativo no município de São Paulo. 2014. 111p. Dissertação (Mestrado em Economia Aplicada) - Universidade Federal de Juiz de Fora, Juiz de Fora, MG, 2014.

CAN, A. GIS and spatial analysis of housing and mortgage markets. Journal of Housing Research, Clemson, v. 9, n. 1, p. 61-86, 1998.

CONSELHO ESTRATÉGICO DE DESENVOLVIMENTO ECONÔMICO DO ALTO PARAOPEBA (CEDECAP). Pilares de Desenvolvimento da Região do Alto Paraopeba. 2015. Disponível em: https://issuu.com/ isaacassilva/docs/merged__1_. Acesso em: 6 jun. 2016.

CONSELHO REGIONAL DE CORRETORES DE IMÓVEIS (CRECI-MG). Conselheiro Lafaiete. [s.d.]. Disponível em: http://www.crecimg.gov.br/outros/sistema/BKP/portalcons.php. Acesso em: 6 jun. 2016. 
COURT, A. T. Hedonic price indexes with automotive examples. The dynamics of automobile demand: New York: General Motors, 1939.

DANTAS, R. A.; MAGALHÃES, A. M.; VERGOLINO, J. R. O. Um modelo espacial de demanda habitacional para a cidade de Recife. Revista Estudos Econômicos, São Paulo, v. 40, n. 4, p. 891-916, out./dez. 2010.

DANTAS, R. A.; MAGALHÃES, A. M.; VERGOLINO, J. R. O. Avaliação de imóveis: a importância dos vizinhos no caso de Recife. Revista de Economia Aplicada, Ribeirão Preto, SP, v. 11, n. 2, p. 231-51, abr./jun. 2007.

FÁVERO, L. P. L.; LUPPE, M. R. Modelos de preços hedônicos aplicados ao mercado imobiliário: uma revisão da literatura. Revista de Economia e Administração, São Paulo, v. 5, n. 4, p. 424-48, 2006.

FERNANDES, A. M. R.; MOREIRA, D. S.; SILVA, R. S. Utilização de um Rede Neural Artificial e Análise Multicritério para determinação do valor de aluguel de apartamentos. In: SIMPÓSIO DE EXCELÊNCIA EM GESTÃO E TECNOLOGIA, 7., 2010, Resende, RJ. Anais [...]. Disponível em: https://www.aedb.br/seget/ arquivos/artigos10/253_seget\%20todim.pdf.

GUJARATI, D. N.; PORTER, D. C. Econometria básica. 5. ed. Porto Alegre: McGraw Hill, 2011.

INSTITUTO BRASILEIRO DE GEOGRAFIA E ESTATÍSTICA (IBGE). Conselheiro Lafaiete. Síntese das informações. 2017. Disponível em: https://cidades.ibge.gov.br/brasil/mg/conselheiro-lafaiete/panorama. Acesso em: 20 abr. 2018.

INSTITUTO BRASILEIRO DE GEOGRAFIA E ESTATÍSTICA (IBGE). Conselheiro Lafaiete. Síntese das informações. 2010. Disponível em: http://www.cidades.ibge.gov.br/xtras/temas.php?lang=\&codmun=31183 0\&idtema=16\&search=minas-gerais | conselheiro-lafaiete | sintese-das-informacoes. Acesso em: 5 jun. 2016.

LANCASTER, K. A new approach to consumer's theory. Journal of Political Economy, Chicago, v. 74, n. 2, p. 132-57, 1966.

LEEUW, F. A price index for new multifamily housing. Survey of Current Business, Washington, v. 73, n. 2, p. 33-42, 1993.

MATTA, T. A. Avaliação do valor de imóveis por análise de regressão: um estudo de caso para a cidade de Juiz de Fora. 2007. 43 p. Monografia (Graduação em Engenharia de Produção) -Universidade Federal de Juiz de Fora, Juiz de Fora, MG, 2007.

MEDEIROS, R. V.; CARVALHO, S. T. Modelagem econométrica do preço de alugueis de apartamentos na cidade de Petrópolis-RJ: utilizando regressão linear múltipla. Revista de Economia da UEG, Anápolis, GO, v. 13, n. 1, p. 157-74, jan./jun. 2017.

PELLI NETO, A. Curso de Engenharia de Avaliação Imobiliária - fundamentos e aplicação da estatística inferencial. Belo Horizonte, MG: [s.n.], 2003.

RAMOS, D. L. Desigualdade urbana e interações espaciais nos preços de imóveis na cidade de Salvador. 2014. 134p. Dissertação (Mestrado em Economia) -Universidade Federal da Bahia, Salvador, 2014.

ROSEN, S. Hedonic prices and implict markets: production differentiation in pure competition. Journal of Political Economy, Chicago, v. 82, n. 1, p. 34-55, 1974.

SERVIÇO NACIONAL DE APRENDIZAGEM COMERCIAL (SENAC). Circuito Villas e Fazendas. Síntese das informações. 2015. Disponível em: http://www.descubraminas.com.br/Turismo/CircuitoDetalhe. aspx?cod_circuito=99. Acesso em: 21 abr. 2018. 


\section{APÊNDICE}

Tabela 1A - Distribuição de imóveis por bairros do município de Conselheiro Lafaiete, MG

\begin{tabular}{|c|c|c|c|c|c|}
\hline Bairro & $\begin{array}{c}\text { № de } \\
\text { imóveis }\end{array}$ & Bairro & $\begin{array}{c}\text { № de } \\
\text { imóveis }\end{array}$ & Bairro & $\begin{array}{c}\text { № de } \\
\text { imóveis }\end{array}$ \\
\hline Albertina & 1 & Jardim Alvorada & 5 & Rosário & 2 \\
\hline Albinópolis & 4 & Jardim América & 2 & Sagr. Cor. de Jesus & 2 \\
\hline Angelica & 3 & Jardim Eldorado & 2 & Santa Efigênia & 4 \\
\hline Arcádia & 6 & Manoel Corrêa & 6 & Santa Luzia & 1 \\
\hline Areal & 3 & Manoel de Paula & 2 & Santa Maria & 1 \\
\hline Bela Vista & 2 & Moinhos & 2 & Santa Matilde & 9 \\
\hline Belvedere & 1 & Morada do Sol & 4 & Santa Rosa & 2 \\
\hline Bom Pastor & 1 & Morro da Mina & 1 & Santo Agostinho & 7 \\
\hline Cachoeira & 2 & Museu & 7 & Santo Antônio & 1 \\
\hline Campo Alegre & 9 & Novo Horizonte & 4 & São Dimas & 3 \\
\hline Carijós & 5 & Parque das Acácias & 3 & São João & 6 \\
\hline Centro & 3 & Paulo VI & 2 & São José & 2 \\
\hline Chapada & 1 & Progresso & 2 & São Sebastião & 5 \\
\hline Cidade Satélite & 1 & Queluz & 1 & Siderúrgico & 1 \\
\hline Expedicionário & 1 & Quintas do Sol & 1 & Sion & 2 \\
\hline Fonte Grande & 1 & Rancho Novo & 1 & Triângulo & 1 \\
\hline Gigante & 1 & Real de Queluz & 1 & Vila Rezende & 2 \\
\hline $\begin{array}{l}\text { Granja das } \\
\text { Hortências }\end{array}$ & 2 & Rochedo & 6 & Total & 150 \\
\hline
\end{tabular}

Fonte: Dados da pesquisa. 
Figura 1 - Concentração dos imóveis amostrados por bairros no municipio de Conselheiro Lafaiete, MG

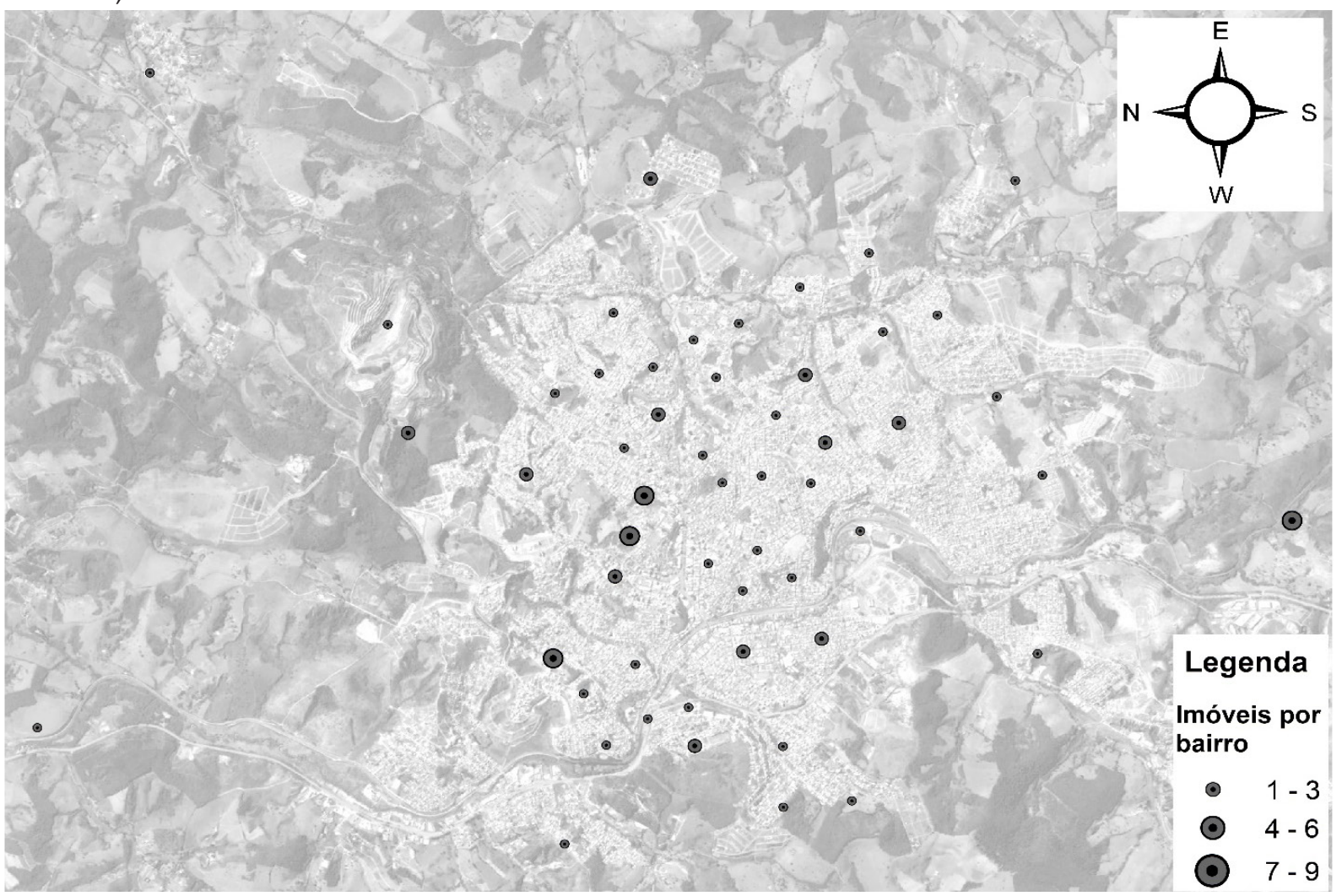

Fonte: Elaboração própria.

\section{Sobre os autores:}

Victor Henrique Lana Pinto: Mestrando no Programa de Pós-Graduação em Economia Aplicada da Universidade Federal de Viçosa - campus Viçosa. Graduado em Ciências Econômicas pela Universidade Federal de Ouro Preto (UFOP). Professor da Universidade Federal de Viçosa - campus Rio Paranaíba. Realiza pesquisas nas áreas de comércio internacional, integração econômica e desenvolvimento regional. E-mail: victorhlp@hotmail.com, Orcid: http://orcid.org/0000-0001-8318-4009

Rosangela Aparecida Soares Fernandes: Doutora e Mestre em Economia Aplicada, e Graduada em Ciências Econômicas pela Universidade Federal de Viçosa (UFV). Professora Associada I no Curso de Graduação em Ciências Econômicas da Universidade Federal de Ouro Preto (UFOP) Campus Mariana e Professora Permanente do Programa de Pós-Graduação em Economia Aplicada (PPEA-UFOP). Tem experiência nas áreas Economia Industrial e Microeconomia, atuando principalmente nos seguintes temas: poder de mercado, defesa da concorrência e condutas anticompetitivas. E-mail: roaeconomista@yahoo.com.br, Orcid: http://orcid.org/0000-0003-3815-0082 
